\title{
Reply to: Broad definitions of enforcement are unhelpful for understanding evolutionary mechanisms of cooperation
}

\author{
J. Arvid Ågren ${ }^{1,4}$, Nicholas G. Davies $\circledast^{2,4}$ and Kevin R. Foster $\left(^{3 \star}\right.$ \\ REPLYING TO S. C. Engelhardt \& M. Taborsky Nature Ecology \& Evolution https://doi.org/10.1038/s41559-019-1088-7 (2020)
}

W hile Engelhardt and Taborsky ${ }^{1}$ agree with the core argument of our recent article ${ }^{2}$ - that enforcement is central to the evolution of cooperation-they go on to suggest that our use of the word 'enforcement' is too broad and that we neglect to distinguish between behavioural manipulations that occur via helping or harming. We find no merit in these points.

First, semantics. Engelhardt and Taborsky object that our use of 'enforcement' does not correspond exactly with their everyday use of the word. The fit between common parlance and the terminology of evolutionary biology is an old concern ${ }^{3}$, but one that can be mitigated by clearly defining terms ${ }^{4}$. Our definition of enforcement-an action that evolves, at least in part, to reduce selfish behaviour within a cooperative alliance-reflects the established usage for describing mechanisms such as partner choice, punishment and reward in cooperative systems across all scales of life (for example, see Fig. 2 in West et al. ${ }^{5}$ ). Moreover, it was precisely because of the subjectivity of language that we also provided an extensive theory supplement that defines enforcement mathematically (see also Box 2 in our original piece $^{2}$ ). Instead, Engelhardt and Taborsky provided an 'everydaylanguage' definition of enforcement ("an action involving manipulation by force to the benefit of an actor at the expense of a receiver") that is so vague, and indeed broad, that it would draw in examples of both predation and parasitism. This illustrates why everydaylanguage definitions are often insufficient for evolutionary biology.

The second key point of Engelhardt and Taborsky is that we do not sufficiently distinguish between enforcement through harm and that which occurs through the provision of incentives or help. Again, we disagree. Our review explicitly distinguished between harming and helping mechanisms of enforcement (see Table 1 in our original piece $^{2}$ ) and gave numerous examples of each. We also reject their point that manipulations by harming versus helping are so different that distinguishing them is 'essential'. Consider, for example, a host controlling its microbial symbionts either by differential harming or differential feeding, as is thought to occur in the mammalian microbiome via various antimicrobial peptides and glycosylated mucins, respectively ${ }^{6}$. To increase the relative abundance of a beneficial symbiont, the host can preferentially feed cooperative symbionts, preferentially intoxicate non-cooperative symbionts, or both. However, importantly, the different mechanisms can have exactly the same evolutionary effects on cooperation. Therefore, while we appreciate that harming and helping mechanisms of enforcement can have their differences ${ }^{2}$, they have a lot more in common to the extent that they will be sometimes indistinguishable in their effects on cooperative evolution. For this reason, it makes a lot of sense to study them together in one framework.

The utility of our framework ${ }^{2}$ becomes clear when one looks beyond Engelhardt and Taborsky's focus on the animal behaviour literature. One of the major advances in evolutionary biology of recent decades is the recognition that the principles of social evolution apply equally to selfish genetic elements, microbes, mutualisms and societies ${ }^{7}$. Restricting focus to animal behaviour ${ }^{1}$ prevents one from recognizing the shared principles and establishing the common vocabulary needed to understand the evolution of cooperation across all biological systems.

Received: 19 November 2019; Accepted: 14 January 2020; Published online: 10 February 2020

\section{References}

1. Engelhardt, S. C. \& Taborsky, M. Broad definitions of enforcement are unhelpful for understanding evolutionary mechanisms of cooperation. Nat. Ecol. Evol. https://doi.org/10.1038/s41559-019-1088-7 (2020).

2. Aggren, J. A., Davies, N. G. \& Foster, K. R. Enforcement is central to the evolution of cooperation. Nat. Ecol. Evol. 3, 1018-1029 (2019).

3. Midgley, M. Gene-juggling. Philosophy 54, 439-458 (1979).

4. Dawkins, R. In defence of selfish genes. Philosophy 56, 556-573 (1981).

5. West, S. A., Griffin, A. S. \& Gardner, A. Evolutionary explanations for cooperation. Curr. Biol. 17, R661-R672 (2007).

6. Foster, K. R., Schluter, J., Coyte, K. Z. \& Rakoff-Nahoum, S. The evolution of the host microbiome as an ecosystem on a leash. Nature 548, 43-51 (2017).

7. Bourke, A. F. G. Principles of Social Evolution (Oxford Univ. Press, 2011).

\section{Acknowledgements}

J.A.Å. is supported by a fellowship from the Wenner-Gren Foundations.

\section{Author contributions}

J.A.Å., N.G.D. and K.R.F. all substantially contributed to the concept, design, drafting and reviewing of the work.

\section{Competing interests}

The authors declare no competing interests.

\section{Additional information}

Correspondence and requests for materials should be addressed to K.R.F.

Reprints and permissions information is available at www.nature.com/reprints.

Publisher's note Springer Nature remains neutral with regard to jurisdictional claims in published maps and institutional affiliations.

(C) Springer Nature Limited 2020

'Department of Organismic and Evolutionary Biology, Harvard University, Cambridge, MA, USA. ²Department of Infectious Disease Epidemiology, London School of Hygiene and Tropical Medicine, London, UK. ${ }^{3}$ Department of Zoology and Department of Biochemistry, University of Oxford, Oxford, UK.

${ }^{4}$ These authors contributed equally: J. Arvid Ågren, Nicholas G. Davies. *e-mail: kevin.foster@zoo.ox.ac.uk 